\title{
Studies on the Reduction of Different Thioxanthenones by Dibutyltin Chloride Hydride
}

\author{
Wojciech J. Kinart ${ }^{a^{*}}$, Andrzej E. Kinart ${ }^{\mathrm{a}}$, Monika Kozak ${ }^{\mathrm{a}}$, Cezary M. Kinart \\ ${ }^{2}$ Department of Organic Chemistry, University of Lodz, Narutowicza 68, \\ 90-136 Lodz, Poland \\ ${ }^{b}$ Department of Physical Chemistry of Liquids, University of Lodz, Pomorska 163, \\ 90-236 Lodz, Poland
}

\begin{abstract}
Thioxanthene (1'), 2-chlorothioxanthene (2') and 1-chloro-4-methylthioxanthene (3') were obtained as products of reduction of thioxanthen-9-one (1), 2-chlorothioxanthen-9-one (2) and 1-chlorothioxanthen-9-one (3) using dibutyltin chlorohydride. The mechanism of this reaction, involving formation of thioxanthyl cations, has been suggested by comparing it with the course of hydrostannation of cyclopropyl-4methoxyphenylmenthon.
\end{abstract}

\section{INTRODUCTION}

Thioxanthenones, like lucanthone (Miracil D) /1-3/ and hycanthone (Etrenol) /4-8/ have been widely known as antischistosomal and anticancer agents. With the discovery of curative anticancer activities in animal modes, this series of compounds, like WIN 33377, advanced into clinical trials /9-12/.

It is also known that particularly chloro-substituted thioxanthenones serve as photoinitiators and sensitizers for use in UV-curable pigmented surface coatings such as screen inks, litho inks and photoresists. For example, 1-chloro-4-propoxythioxanthen-9-one has been shown $/ 13,14 /$ to give advantages in cure speed, depth cure and degree of crosslinking when compared with isopropylthioxanthenone, which is generally regarded as the industrial standard for these systems. It has also been reported by Green $/ 15 /$ that the cure speeds of 1-chloro-4-propxythioxathone were higher compared with 4-propoxythioxanthenone. According to him chloro-substitution has a positive effect on the photoactivity. Schuster $/ 16 /$ reported that thioxanthenone triplet is photoreduced by amines via charge-transfer or exciplex intermediate to thioxanthyl ketyl radical. Thioxanthenol or ditioxanthyl pinacol formed from it are easily oxidized material. The former is reported to disproportionate on heating to thioxanthene and thioxanthenone. Ochlschlaeger /17/ reported a simple method of reduction of thioxanthenone to 10-thioxanthenol using sodium added 10 a mixture of mercury and thiaxanthenone suspended in ethanol. Recently, Marcinek /18/ demonstrated spectroscopically the 
intermediacy of the transition radical cation in sequential oxidation processes upon photolysis of thioxanthene. Similar stepwise oxidation processes have also been demonstrated for other NADH analogues 119\%. A quantitative oxidation of thioxanthene during such process leads to thioxanthenone. Previously we have carried out comparative studies on the hydrostannation of acetophenone by different tin hydrides $/ 20 \%$. No reaction occurred between tributyltin hydride or dibutyltin dihydride and acetophenone, but the hydrides $\mathrm{Bu}_{2} \mathrm{SnXH}$ did react in a few hours to give 1-phenylethanol.

\section{EXPERIMENTAL}

NMR spectra were recorded using a Varian Gemini 200 BP spectrometer.

Thioxanthen-9-one (1), 2-chlorothioxanthen-9-one (2) and 1-chloro-4-methylthioxanthen-9-one (3) were commercial samples.

Dibutyltin dihydride was prepared by treatment of dibutyltin dichloride with lithium aluminium hydride in over $50 \%$ excess as described by van der Kerk $/ 21 /$. Subsequent ether extraction and distillation gave the required dihydride in quantitative yield.

Dibutyltin chloride hydride was prepared by disproportionation reaction between dihydride and dibutyltin dichloride $22 \%$. The equilibrium was reached within few minutes and it was shifted towards $\mathrm{Bu}_{2} \mathrm{SnClH}$.

We have carried out reduction of thioxanthen-9-one (1), 2-chlorothioxanthen-9-one (2) and 1-chloro-4methylthioxanthen-9-one (3) using dibutyltin chlorohydride $\left(\mathrm{Bu}_{2} \mathrm{SnClH}\right)$.

A typical example of reduction of thioxanthenones was as follows: $235 \mathrm{mg}$ (1mmol) of dibutyltindihydride $\left(\mathrm{Bu}_{2} \mathrm{SnH}_{2}\right)$ and $303 \mathrm{mg}(1 \mathrm{mmol})$ of dibutyltin dichloride $(1 \mathrm{mmol})$ were added to $10 \mathrm{ml}$ of benzene. After 30 minutes, when the equilibrium leading to formation of $\mathrm{Bu}_{2} \mathrm{SnClH}$ was reached, $212 \mathrm{mg}$ ( $1 \mathrm{mmol}$ ) of thioxanthen-9-one was added. The progress of the reaction was monitored by TLC and ${ }^{1} \mathrm{H}$ NMR spectroscopy. After 48 hours the product of the reaction was purified by column chromatography, using a mixture of ethyl acetate and petroleum ether $(3 / 7, v / v)$. The product obtained in quantitative yield was identified as thioxanthene (1). It was obtained after purification in the form of colorless needless (cyclohexane), mp $134-135^{\circ} \mathrm{C}$. Its ${ }^{1} \mathrm{H}$ NMR spectrum was analogous to that reported in the literature $23 /$.The same procedure was repeated for 2-chlorothioxanthen-9-one and 1-chloro-4-methylthioxanthen-9-one. It led to the formation of 2-chlorothioxanthene (2') and 1-chloro-4-methylthioxanthene (3') respectively. Their ${ }^{1} \mathrm{H}$ NMR spectra were characterized by the following chemical shifts:

2-Chlorothioxantene (2') $\mathrm{mp} 101-103^{\circ} \mathrm{C} / 24 /$

$\delta_{\mathrm{H}}\left(\mathrm{CDCl}_{3}\right): 3.82(2 \mathrm{H}, \mathrm{s}), 7.19(4 \mathrm{H}, \mathrm{m}), 7.32(2 \mathrm{H}, \mathrm{m}), 7.45(1 \mathrm{H}, \mathrm{ddd}, \mathrm{J}=7.4,7.4,1.9 \mathrm{~Hz})$

2-chloro-4-methylthioxanthene (3') $\mathrm{mp} 91-92^{\circ} \mathrm{C}$

$\delta_{\mathrm{H}}\left(\mathrm{CDCl}_{3}\right): 2.43(3 \mathrm{H}, \mathrm{s}), 4.07(2 \mathrm{H}, \mathrm{s}), 7.02(1 \mathrm{H}, \mathrm{d}, \mathrm{J}=8.2 \mathrm{~Hz}), 7.24(3 \mathrm{H}, \mathrm{m}), 7.40(1 \mathrm{H}, \mathrm{ddd}, \mathrm{J}=7.4,7.4$, $1.9 \mathrm{~Hz}), 7.49(1 \mathrm{H}$, ddd, $\mathrm{J}=7.4,7.4,1.9 \mathrm{~Hz})$.

Low-resolution mass spectra (MS) of (1), (2') and (3') were taken using chemical ionization (Cl) technique with a Finningan MAT 95 instrument (source temperature of ca. $200^{\circ} \mathrm{C}$, reagent gas - isobutan, 
accelerating voltage of $4.8 \mathrm{kV})$. MS $(\mathrm{Cl}) \mathrm{m} / \mathrm{z}=199.058,233.019$ and $247.105(\mathrm{M}+1)$ corresponding to abovementioned thioxanthenes. Calculated values of $(M+1)$ were equal respectively to $199.3,233.7$ and 247.7.

Tributyl(cyclopropyl-4-methoxyphenylmethoxy)tin was prepared by azeotropic dehydration, carried out in toluene, of a mixture of $2 \mathrm{mmol}(256 \mathrm{mg}$ ) of cyclopropyl-4-methoxyphenylmethanol (obtained by reduction of cylopropyl-4-methoxyphenylmethanon using $\left.\mathrm{LiAlH}_{4}\right)$ and 1 mmol $(596 \mathrm{mg}$ ) of bis(tributyltin)oxide.

\section{RESULTS AND DISCUSSION}

The products of reduction of three different tioxanthen-9-ones (1), (2) and (3) by dibutyltin chloride hydride $\left(\mathrm{Bu}_{2} \mathrm{SnClH}\right)$ have been identified as corresponding to the derivatives of thioxanthene $\left(1^{\prime}\right),\left(2^{\prime}\right)$ and (3).

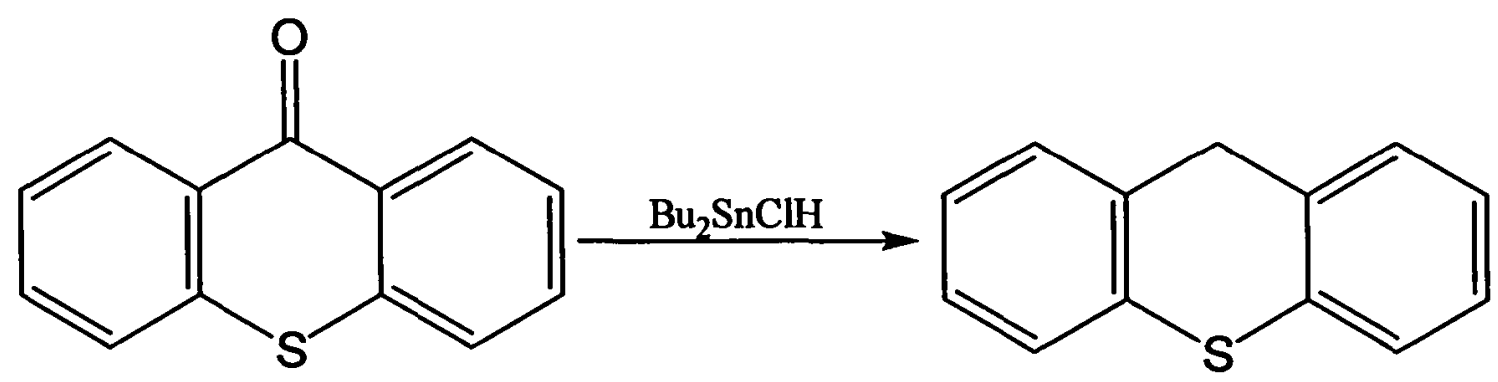

(1)

\section{Scheme 1}

(1)

We have previously $125 /$ observed the analogous course of the reduction for cyclopropyl-4methoxyphenylmetanon by $\mathrm{Bu}_{2} \mathrm{SnClH}$. It has been well documented that reduction of thioxanthen-9-one using traditional methods $/ 17 /$ (sodium being added to a mixture of mercury and the solution of thioxanthenone in $95 \%$ alcohol) leads to 10-thioxanthenol, which is unstable and undergoes the disproportionation reaction to thioxanthene and thioxanthen-9-one. It has been also confirmed that transition ketyl radical is formed during sequential oxidation process of thioxanthene $/ 19 /$.

We have previously $/ 21 /$ studied the process of reduction of acetophenone by $\mathrm{Bu}_{2} \mathrm{SnClH}$ carried at room temperature. Tin derivative of 1-phenylethanol has been obtained in few hours as its product.

We were presently anxious to suggest a new mechanism of reduction of bulky phenyl ketones using mixed hydrides.

In purpose to exclude from further considerations the mechanism involving formation of tin derivative of alcohol corresponding to reduced ketone in the course of such reduction, we have synthesized relatively stable cyclopropyl-4-methoxyphenymethanol and transformed it into tributyl(cyclopropylomethoxyphenylmethoxy)tin. Its hydrolysis led to the starting alcohol without formation of any disproportionation 
products. Also analysis of products of reduction of three studied thioxanthen-9-ones carried out using 2 eqiv. of $\mathrm{Bu}_{2} \mathrm{SnClH}$ indicated formation in nearly quantitative yield of the corresponding derivatives of thioxanthenes. No trace of thioxanthen-9-ones, formed according to the potentially possible disproportionation reaction of thioxanthen-9-oles, was detected. Although the mechanism of the studied stepwise reduction is still a matter of speculation, it seems correct to exclude, for bulky phenyl ketones (like thioxanthenones or cyclopropyl-4-methoxyphenylmenthone) being reduced by $\mathrm{Bu}_{2} \mathrm{SnClH}$, the formation of the corresponding alcohols or their tin derivatives as the intermediate products. It is also probable for such systems to postulate formation of thioxanthyl cations in the transition state. The complete explanation of this composed mechanism will require further studies.

\section{REFERENCES}

1. D. A. Berberian, H. Freeele, D. Rosi, E. W. Dennis, S. J. Archer. Parasitol 53, 306-311 (1967)

2. C. W. Haidle, B. R. Brinkley, M. J. Mandel, Bacteriol 102, 835-842 (1972)

3. E. Hirschberg, I. B. Weinstein, N. Gersten, E. Marner, T. Finkelstein, R. Carchman, Cancer Res. 28, 601-607 (1968).

4. S. Turner, R. Bases, A. Pearlman, M. Nobler, B. Kabakow, Radiology 114, 729-731 (1975).

5. D. Rosi, G. Peruzzotti, E. W. Dennis, D. A. Berberian, H. Freele, B. F. Tullar, S. J. Archer, Med. Chem. 10, 867-876 (1967).

6. E. Hirschberg, I. B. Weinstein, Science 174, 1147-1148 (1971)

7. A. Ruas, Cent. Afr. J. Med. 18, 109-112 (1972)

8. S. Archer, L. Pica-Mattoccia, D. Coli, A. Seyed-Mozaffari, A. H. Zayed, J. Med. Chem. 31, 254-260 (1988)

9. J. P. Stevenson, D. DeMaria, D. Reilly, J. D. Purvis, M. A. Graham, G. Lockwood, M. Drozd, P. J. O'Dwyer, Cancer Chemotherapy and Pharmacology 44, 228-234 (1999)

10. E. Izbicka, R. Lawrence, K. Davidson, J. B. Rake, D. D. Von Hoff, Investigational New Drugs 16, 221225 (1998-1999)

11. R. B. Perni, M. P. Wetland, J. I. Huang, R. G. Powles, S. Aldous, K. M. Klingbeil, A. D. Peverly, A. G. Robinson, T. H. Corbett, J. L. Jones, K. C. Mattes, J. B. Rake, S. A. Coughlin, J. Med. Chem. 41, 36453654 (1998)

12. M. P. Wentland, R. B. Perni, R. G. Powles, A. G. Hlavac, K. C. P. Mattes,, P. Thomas, H. Corbett, S. A. Coughlin, J. B. Rake, Bioorg. Med. Chem. Lett. 4, 609-614 (1994)

13. W. A. Green, A. W. Timms, P. N. Green, Radtech Europe 636 (1991)

14. W. A. Green, A. W. Timms, P. N. Green, Radtech North America 33 (1992)

15. W. A. Green, A. W. Timms, Eur. Plym. P. C. J., 183, 41 (1993)

16. S. F. Yates, G. B. Schuster, J. Org. Chem. 49, 3349-3356 (1984)

17. H. F. Oehlschlaeger, I. R. MacGregor, J. Am. Chem Soc. 72, $5332-5333$ (1950)

18. A. Marcinek, J. Rogowski, J. Adamus, J. Gębicki, M. S. Platz, J. Phys. Chem., 100, 13539-13543 
(1996)

19. S. Fakuzami, T. Tanaka, In Photoininduced Electron Transfer, M. A. Fox, M. Chanon, Eds., Elsevier: Amsterdam, 1998; Part C, pp 578-635

20. A. G. Davies, W. J. Kinart, D. K. Osei-Kissi, J. Organomet. Chem., 474, C11-12 (1994)

21. G. Van der Kerk, J. G. Noltes, L. G. A. Luijten, J. Appl. Chem. 7, 366-369 (1957)

22. A. K. Sawyer, J. E. Brown, J. Organomet. Chem. 5, 438- (1966)

23. T. Takido, Y. Takagi, K. Itabashi, J. Heterocyclic Chem. 32, 687-690 (1995)

24. J. F. Muren, B. H. Bloom, J. Med. Chem. 13 (1), 14-16 (1970)

25. W. J. Kinart, unpublished results 
